\title{
A microbial ecosystem: agricultural Jiaosu achieves effective and lasting antifungal activity against Botrytis cinerea
}

Yue Zhang ${ }^{1}$, Youhui Gao' ${ }^{1}$ Zehui Zheng ${ }^{1}$, Xingyao Meng ${ }^{2}$, Yafan Cai ${ }^{3}$, Jianbin Liu', Yuegao Hu' ${ }^{1}$, Shuangdui Yan ${ }^{5}$ and Xiaofen Wang ${ }^{1 *}$

\begin{abstract}
Synthetic fungicides are eco-unfriendly to agriculture and the environment. Agricultural Jiaosu (AJ), which originates from organic wastes, has the potential to be a substitute for synthetic fungicides. In this study, the characteristics of AJ and its antifungal activity against Botrytis cinerea were investigated for the first time. AJ was rich in lactic acid (4.46 g/L), acetic acid (1.52 g/L), Lactobacillus (72.45\%) and Acetobacter (15.23\%), which was a microbial ecosystem consisting of acid-based substances (AS) and beneficial microorganisms (BM). The results of the antifungal assays suggested that $B$. cinerea was effectively inhibited by $A J$, with the half-maximal inhibitory concentration $\left(I_{50}\right)$ of $9.24 \%$. AJ showed the strongest and most-lasting inhibitory effect compared to cell-free supernatant and microbial solution of $A J$, indicating that $A S$ and BM and their synergistic effect contributed to the antifungal activity of AJ. Two-step inhibition' is an antifungal mode of AJ. Firstly, AS not only inhibited the pathogen directly but also provided a dominant niche for BM of AJ. Then, BM in AJ, especially Acetobacter, proliferated and metabolized acetic acid continuously. Thus, $\mathrm{AJ}$ achieved high-efficiency and long-acting inhibition. AJ is a promising biological agent considering its features of an eco-friendly, low-cost and easy-to-operate biological agent in rural areas.
\end{abstract}

Keywords: Agricultural Jiaosu, Antifungal activity, Biological agent, Synergistic effects, Botrytis cinerea

\section{Key points}

1. The antifungal activity of $\mathrm{AJ}$ against $B$. cinerea was studied for the first time.

2. AJ was an ecosystem and achieved an effective and lasting antifungal activity.

3. $A S, M B$ and their synergistic effect contributed to higher inhibitory rate.

\footnotetext{
*Correspondence: wxiaofen@cau.edu.cn

${ }^{1}$ College of Agronomy and Biotechnology, China Agricultural University, Beijing 100193, China

Full list of author information is available at the end of the article
}

\section{Introduction}

Phytopathogenic fungi can infect soil and crops, resulting in heavy losses of yield, quality and economy. Botrytis cinerea is a common and extremely harmful soil-borne pathogen in agricultural production, which can attack the leaves, flowers and fruits of crops (Santos et al. 2004). Grey mould disease caused by $B$. cinerea occurs on at least 200 plants, especially cash crops, such as vegetables, fruits and medicinal herbs (Panebianco et al. 2015; Xu et al. 2017). B. cinerea is a haploid, necrotrophic and heterothallic ascomycete. The complicated aetiology and the multiple ways of aerial growth make it difficult to prevent and control $B$. cinerea (Jeong et al. 2013). At present, several chemical fungicides are used to control B. cinerea, including hydroxyanilides, phenylpyrroles, anilinopyrimidines, dicarboximides and carboxamides (Myresiotis et al. 
2007). This method is not recommended due to its negative impact on the environment and safety production. More seriously, the long-term application of synthetic fungicides leads to resistance to pathogens and reduces biodiversity (Yildirm and Yapici 2007; Sun et al. 2019; Baraldi et al. 2002). Therefore, it is essential and urgent to develop ecological and sustainable methods to reduce or replace synthetic fungicides (Aqueveque et al. 2017; Rosado-Álvarez et al. 2014).

Currently, substitutes for synthetic fungicides mainly include botanical fungicides and biological agents. Botanical fungicides such as essential oils, chitosan and terpenoids have been reported to have antifungal activity against $B$. cinerea (Aqueveque et al. 2017; Ben-Shalom et al. 2003; Bi and Yu 2016). Biological agents such as Lactobacillus, Saccharomyces cerevisiae and Bacillus licheniformis are effective antagonistic microorganisms (Santos et al. 2004; Trias et al. 2008; Lee et al. 2006). The inhibitory effect of botanical fungicides is stable, but the complex extraction process and high cost make it impossible to apply for all farmers to use. Although biological agents are sustainable, they are not widely used due to cumbersome operation and unstable activity. Thus, highefficiency, low-cost and eco-friendly products are essential, which should be an ecosystem rich in antifungal substances and antagonistic microorganisms to ensure the inhibitory effect and offset the above shortcomings.

In recent years, Agricultural Jiaosu (AJ) attracts widespread attention and large-scale application as a biological agent in agricultural practice in China. AJ has many advantages, such as sustainability, stabilisation, handleability, low-cost and use of simple equipment. This novel biotechnology can break the bottleneck of fungicides. In general, the $\mathrm{AJ}$ is diluted 1:200-500 times and applied to farmland once every 3-7 days. The dosage is about 2-3 $\mathrm{L} / \mathrm{m}^{2}$. According to the Light Industry Standards of the People's Republic of China of the Guidelines for Jiaosu Products Classification and Plant Jiaosu, AJ is defined as an ecological product made via fermentation using organic wastes as substrates (MIIT-China 2018a, b). Previous studies have shown that $\mathrm{AJ}$ contains acid-based substances (AS), such as lactic acid (LA) and acetic acid (AA), and beneficial microorganisms (BM), such as lactic acid bacteria (LAB) and acetic acid bacteria (AAB); (Selvakumar and Sivashanmugam 2017; Arun and Sivashanmugam 2015; Rahman et al. 2020; Di et al. 2020), which are verified to show the inhibitory ability against $B$. cinerea (Trias et al. 2008; Drysdale and Fleet 1989; Golnaz Hesami 2013; Lagopodi et al. 2009; De Corato et al. 2014; De Vuyst and Leroy 2020). As an ecosystem of AS and $\mathrm{BM}, \mathrm{AJ}$ has displayed a strong antifungal activity in rural regions of China. However, systematic research is insufficient in the academic community. Scientific experiments are urgently needed to provide theoretical support for the application of AJ.

There is no relevant literature on the antifungal potential of AJ on phytopathogens. In this study, the antifungal activity and mechanism of $\mathrm{AJ}$ against $B$. cinerea were investigated for the first time. The research was divided into five aspects: (1) physicochemical properties and microbial characteristics of AJ, (2) changes in the antifungal activity of AJ with dosage, (3) dynamic changes in the inhibitory effect of AJ with cultivation time, (4) main inhibitory factors of AJ and (5) antifungal mode by the synergistic effect between AS and BM of AJ.

\section{Materials and methods \\ $\mathrm{AJ}$ and pathogen}

Brown sugar $(400 \mathrm{~g})$ and jujube wastes $(1200 \mathrm{~g})$ were mixed with $4 \mathrm{~L}$ distilled water in air-tight containers for anaerobic fermentation at $30{ }^{\circ} \mathrm{C}$ for 3 months and stirred once a week. A large number of jujube wastes were produced when farmers harvest at an organic orchards in Jishan County, Shanxi Province, China. Then these wastes were collected to fermentation. The composition of jujube wastes was described by Guo (2019). AJ was centrifuged at $5000 \mathrm{rpm}$ for $15 \mathrm{~min}$. The supernatant was used for further experiments. The volume of the bottle was $5 \mathrm{~L}$ with the working volume of $4 \mathrm{~L}$. And mixing the whole fermented system with a stirring rod once a week.

Botrytis cinerea (ACCC 36028) was purchased from the Agricultural Culture Collection of China (Beijing, China). The pathogen was cultured on potato dextrose agar (PDA) medium at $25^{\circ} \mathrm{C}$ before the experiments.

\section{Characterisation of AJ}

The $\mathrm{pH}$ values of $\mathrm{AJ}$ were determined by a micro-pH metre (Mettler-Toledo, Greifensee, Switzerland). LA and AA were measured using high-performance liquid chromatography with a diode array detector (SPD-M20A; Shimadzu, Kyoto, Japan). The samples were mixed with acetonitrile at a 1:1 ratio for $10 \mathrm{~min}$ and then filtered through a $0.22 \mu \mathrm{m}$ filter. The details of the chromatographic procedure and conditions were described by Cai et al. (2018a, b).

Man-Rogosa-Sharpe agar was used for the total microbial counts of LAB. AAB counts were determined by a special medium (10 g yeast extract, $10 \mathrm{~g}$ dextrose, $20 \mathrm{~g} \mathrm{CaCO}_{3}, 0.015 \mathrm{~g}$ bromocresol purple, $15 \mathrm{~g}$ agar, $\mathrm{pH}$ $6.8 \pm 0.2)$. High-throughput sequencing was performed on an MiSeq platform (Personalbio Company, Shanghai, China). The $\mathrm{V}_{3}-\mathrm{V}_{4}$ hypervariable region of the bacteria was amplified using the following universal primer set: 338F (5'-ACTCCTACGGGAGGCAGCA-3 $\left.{ }^{\prime}\right)$ and 806R (5'-GGACTACHVGGGTWTCTAAT- ${ }^{\prime}$ ). The community structure was analysed by Silva database at 
the phylum and gene levels (Zhao et al. 2017). The highthroughput sequencing raw data was deposited in the NCBI Sequence Read Archive database and the accession number was SRR12726966.

\section{Effect of dosage of $A J$ on the antifungal activity against $B$. cinerea}

Blank control (CK) was prepared without the addition of AJ, whereas $5,15,25$ and $50 \mathrm{~mL} \mathrm{AJ}$ were added into 95 , 85,75 and $50 \mathrm{~mL}$ autoclaved PDA medium to create the dosage of $5 \%, 15 \%, 25 \%$ and $50 \%$, respectively, and then shaken gently and poured into the dish. After agar gelling, the mycelial plugs (circle disks) of $B$. cinerea were cut using a $5 \mathrm{~mm}$ cork borer sterilised by flame. The plugs were placed at the centre of the plate with different dosages and then incubated at $25{ }^{\circ} \mathrm{C}$ for $72 \mathrm{~h}$. The colony diameter was measured every $24 \mathrm{~h}$. All measurements were performed three times. The inhibitory rate was calculated using the following formula (Kuwaki et al. 2002):

$$
\eta=\frac{[D c k-D i]}{D i} * 100
$$

where $\eta$ is the inhibition rate (\%), which is indicative of antifungal activity, and $D_{\mathrm{ck}}$ and $D_{\mathrm{i}}$ represent the colony diameter of the pathogen of CK and treatments $(\mathrm{mm})$, respectively.

The half-maximal inhibitory concentration $\left(\mathrm{IC}_{50}\right)$ refers to the concentration required for a drug to inhibit cell growth and virus replication by $50 \%$, which is one of the important parameters commonly used in toxicology. Taking the $72 \mathrm{~h}$ colony diameter as the $y$-value and the dosage of $\mathrm{AJ}$ as the $x$-value, quadratic regression analysis was performed to obtain the fitting curve and polynomial equation. Half of the colony diameter of CK was taken as the $y$-value and entered it into the formula to get the corresponding $x$-value, which is the $\mathrm{IC}_{50}$ of AJ against $B$. cinerea (Cai et al. 2018a, b).

\section{Effect of $A J$, cell-free supernatant and microbial solution on the antifungal activity against $B$. cinerea}

To reveal the inhibitory factors, an antifungal assay was carried out with the following treatments on AJ: T1, without any treatments; T2, $3 \mathrm{~mL}$ AJ was centrifuged at $120,00 \mathrm{rpm}$ for $10 \mathrm{~min}$, and the supernatant was filtered through a $0.22 \mu \mathrm{m}$ sterile syringe filter (Millex GP, Cork, Ireland) and T3, the precipitate of $\mathrm{T} 2$ was washed with sterile water and centrifuged at $12,000 \mathrm{rpm}$ for $10 \mathrm{~min}$, and the supernatant was removed. This operation was repeated three times. Finally, the pellet was mixed with $3 \mathrm{~mL}$ sterile water. The same amount of sterile water was used as control (CK). Under the premise of 5\% dosage, $19 \mathrm{~mL}$ sterile PDA medium was poured into each culture dish. After the medium has cooled and solidified, $1 \mathrm{~mL}$
AJ with different treatments was spread onto the surface of fresh PDA medium until drying and then the $5 \mathrm{~mm}$ plug was placed at the centre (Kazemipoor et al. 2012) and then incubated at $25^{\circ} \mathrm{C}$ for $72 \mathrm{~h}$. The colony diameter was measured every $24 \mathrm{~h}$. Each treatment was repeated three times.

\section{Dynamic changes in $\mathrm{pH}, \mathrm{LA}$ and $\mathrm{AA}$ during the inhibition process}

The above experiment was repeated in PDA medium without agar. The samples were collected at $0,12,24,36$, 48,60 and $72 \mathrm{~h}$ to determine the $\mathrm{pH}$ value and the concentrations of LA and AA using the methods mentioned above.

\section{Quantitative polymerase chain reaction (qPCR) analysis of $B$. cinerea, Lactobacillus and Acetobacter during the inhibition process}

The gene concentrations of B. cinerea, Lactobacillus and Acetobacter were assessed. Sample DNA was obtained at $0,12,24,36,48,60$ and $72 \mathrm{~h}$ during the inhibition process of the above experiments. Real-time qPCR analyses were performed using the $\mathrm{ABI}$ fluorescence $\mathrm{qPCR}$ instrument (Model 7500; Applied Biosystems, Foster City, CA, USA). PCR consisted of $10 \mu \mathrm{L}$ using SYBR $^{\circledR}$ Green PCR SuperMix-UDG Kit [Invitrogen, Carlsbad, CA, USA; $0.4 \mu \mathrm{L}$ Rox dye $(10 \times), 0.4 \mu \mathrm{L}$ primer-F, $0.4 \mu \mathrm{L}$ primer-R], DNA template $(1.0 \mu \mathrm{L})$ and double-distilled water to a total volume of $20 \mu \mathrm{L}$. The reported units were copies $/ \mathrm{mL}$. The PCR primers and the amplification protocol are given in Additional file 1: Tables S1 and S2, respectively.

\section{Data analysis}

Statistical analyses were evaluated based on completely randomised variance at $P<0.05$ using Statistix 8.1.1 software (Turntech, Beijing, China). Excel 2016 (Microsoft, Inc., Seattle, WA, USA) was used to compute the mean \pm standard deviation (SD) and graphical presentation.

\section{Results}

\section{Characteristics of AJ}

To evaluate the antifungal activity of AJ, its characteristics were determined. The main parameters are shown in Table 1 . The $\mathrm{pH}$ value was $3.48 \pm 0.02$. The main organic acids were LA and AA, with a concentration of $4.46 \pm 0.04$ and $1.52 \pm 0.02 \mathrm{~g} / \mathrm{L}$, respectively. Formic acid (FA), propionic acid (PA) and butyric acid (BA) were not detected. The colony counts of $\mathrm{LAB}$ and $\mathrm{AAB}$ were $4.78 \pm 3.30$ and $4.30 \pm 2.90 \log$ colony-forming units $(\mathrm{CFU}) / \mathrm{mL}$, respectively.

High-throughput analyses were used to detect the bacterial diversity of AJ. Figure 1 shows the bacterial 
Table 1 Characteristics of AJ

\begin{tabular}{ll}
\hline Parameter & Value \\
\hline $\mathrm{pH}$ & $3.48 \pm 0.02$ \\
$\mathrm{LA}(\mathrm{g} / \mathrm{L})$ & $4.46 \pm 0.04$ \\
$\mathrm{FA}(\mathrm{g} / \mathrm{L})$ & $\mathrm{ND}$ \\
$\mathrm{AA}(\mathrm{g} / \mathrm{L})$ & $1.52 \pm 0.02$ \\
$\mathrm{PA}(\mathrm{g} / \mathrm{L})$ & $\mathrm{ND}$ \\
$\mathrm{BA}(\mathrm{g} / \mathrm{L})$ & $\mathrm{ND}$ \\
$\mathrm{LAB}(\log C F U / \mathrm{mL})$ & $4.78 \pm 3.30$ \\
$\mathrm{AAB}(\log C F U / \mathrm{mL})$ & $1.30 \pm 2.90$
\end{tabular}

$N D$ not detected

Mean \pm SD $(n=3)$

community at the phylum level (a) and genus level (b). Firmicutes and Proteobacteria dominated the entire community, with relative abundances of $72.80 \%$ and $15.10 \%$, respectively. At the genus level, Lactobacillus (72.45\%) and Acetobacter (15.23\%) occupied the dominant niche.

AJ was an acidic ecosystem consisting of AS (e.g., LA and AA) and BM (e.g., Lactobacillus and Acetobacter). It was speculated that AJ had antifungal potential based on its characteristics.

\section{Effect of dosage of AJ on the antifungal activity against $B$. cinerea}

Dosage is a key factor that affects the antifungal activity in toxicological studies. The effect of the dosage of AJ on its inhibitory effect against $B$. cinerea was investigated (Fig. 2). CK showed the largest colony diameter $(52.49 \mathrm{~mm})$ compared to other dosages at $72 \mathrm{~h}(P<0.05)$, which indicated that $\mathrm{AJ}$ had a negative impact on the growth of $B$. cinerea. The pathogen was almost completely suppressed when the dosage of AJ was more than
$15 \%$ of the whole medium. Also, the inhibitory rate was positively correlated with dosage and cultivation time. At $48 \mathrm{~h}$, the value of this parameter at dosages of $5 \%, 15 \%$, $25 \%$ and $50 \%$ was $10.95 \%, 58.79 \%, 74.89 \%$ and $73.17 \%$, respectively, but there was no significant difference between the latter two treatments $(P>0.05)$. Interestingly, when the time was prolonged to $72 \mathrm{~h}$, the inhibitory rate climbed to $42.36 \%, 74.54 \%, 84.27 \%$ and $85.98 \%$, respectively. The inhibition rates of the latter two treatments (25\% and 50\%) were significantly higher than those of the former two treatments ( $5 \%$ and $15 \%, P<0.05$ ), but there was no significant difference between them $(P>0.05)$. At this moment, the antifungal activity was $2.87,0.27,0.13$ and 0.18 times higher than those at $48 \mathrm{~h}$.

$\mathrm{IC}_{50}$ was calculated according to the above experimental data using Excel 2016. With the colony diameter on the $y$-axis and the dosage on the $x$-axis, the fitting formula was obtained as follows: $Y=0.0382 x^{2}-$ $2.7089 x+48.021, R^{2}=0.9519$. Half of the colony diameter of $\mathrm{CK}$ at $72 \mathrm{~h}(26.245 \mathrm{~mm})$ was introduced into the formula as the $y$-value, and then $\mathrm{IC}_{50}$ was taken as the corresponding $x$-value. The $\mathrm{IC}_{50}$ of $\mathrm{AJ}$ against $B$. cinerea was 9.24\% (Additional file 1: Fig. S1), which is of great importance for practical production.

\section{Antifungal activity of $A J$, cell-free supernatant and microbial solution on $B$. cinerea}

To determine the main inhibitory factors, AJ was divided into two fractions and the antifungal assay was performed (Table 2). T2 and T3 represented AS and $\mathrm{BM}$ of $\mathrm{AJ}$, respectively. $\mathrm{T} 1$ was the ecosystem of $\mathrm{T} 2$ and T3, which was an ecosystem consisting of AS and BM. The inhibitory effect of each treatment was varied in different periods. At the early stage $(24 \mathrm{~h})$, the

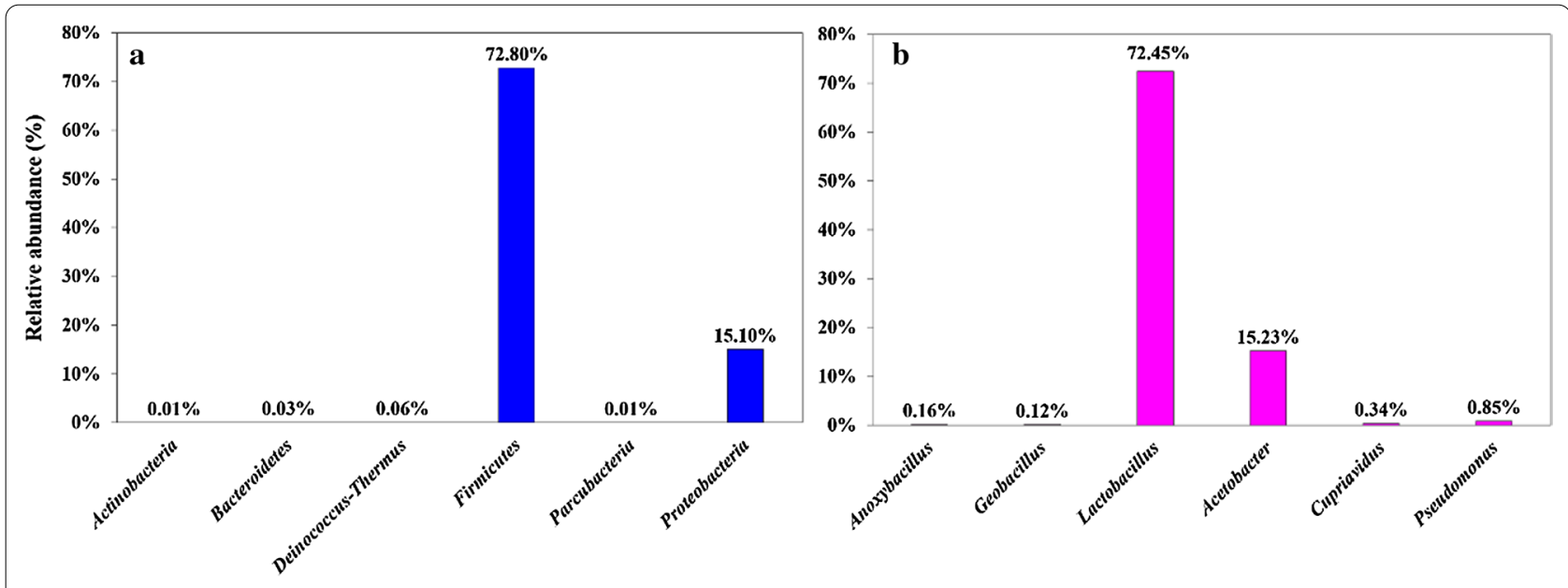

Fig. 1 Bacterial communities of AJ: a phylum level and $\mathbf{b}$ genus level 


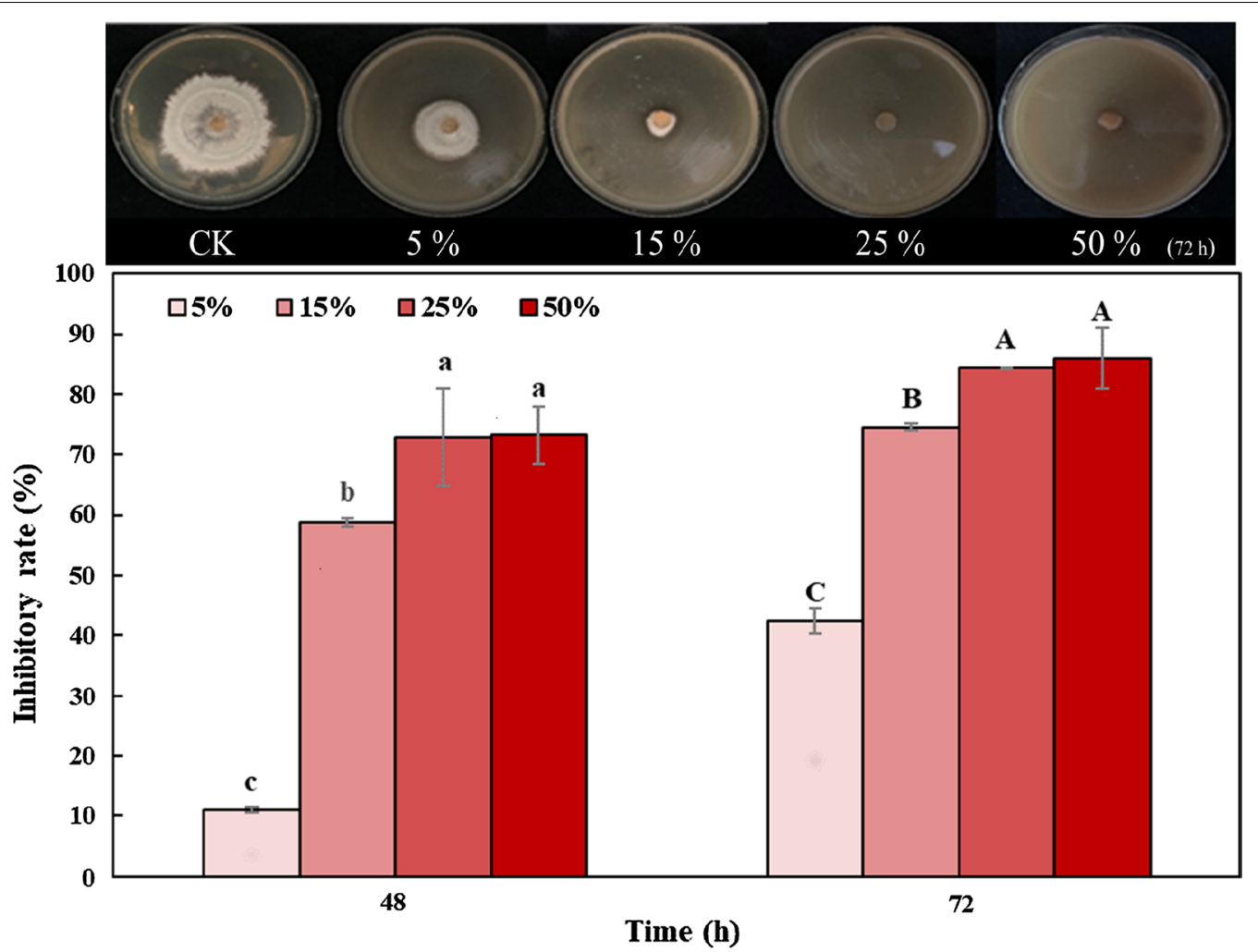

Fig. 2 Inhibitory rate at different dosages (photos taken at $72 \mathrm{~h}$ )

Table 2 Colony diameter of $B$. cinerea under different treatments

\begin{tabular}{|c|c|c|c|c|}
\hline \multirow[t]{2}{*}{ Time (h) } & \multicolumn{4}{|c|}{ Colony diameter (mm) } \\
\hline & CK & $\mathrm{T} 1$ & $\mathrm{~T} 2$ & T3 \\
\hline 24 & $25.78 \pm 0.45^{\mathrm{a}}$ & $22.48 \pm 0.40^{b}$ & $22.95 \pm 0.35^{b}$ & $25.48 \pm 0.46^{\mathrm{a}}$ \\
\hline 48 & $38.04 \pm 0.27^{\mathrm{a}}$ & $27.65 \pm 0.61^{c}$ & $29.63 \pm 0.68^{b}$ & $37.91 \pm 0.62^{\mathrm{a}}$ \\
\hline 72 & $49.27 \pm 0.24^{\mathrm{a}}$ & $35.78 \pm 0.49^{d}$ & $40.29 \pm 0.56^{c}$ & $47.30 \pm 0.41^{b}$ \\
\hline Photo (72 & & & & \\
\hline
\end{tabular}

CK: blank control using sterile water; T1: AJ, a microbial ecosystem consisting of AS and BM; T2: cell-free supernatant of AJ, only AS; T3: microbial solution of $A \mathrm{~J}$, only $\mathrm{BM}$

Mean \pm SD ( $n=3)$. Significant differences at $P<0.05$

colony diameter of $\mathrm{CK}$ was $25.78 \pm 0.45 \mathrm{~mm}$, which was not significantly different from that of T3 $(P>0.05)$ but significantly larger than that of $\mathrm{T} 1$ and $\mathrm{T} 2(P<0.05)$. At $48 \mathrm{~h}$, the colony diameter of T1 was significantly smaller than that of the other three treatments $(P<0.05)$, but there was no significant difference between $\mathrm{T} 3$ and CK $(P>0.05)$. The colony diameter at $72 \mathrm{~h}$ of $\mathrm{CK}, \mathrm{T} 1, \mathrm{~T} 2$ and T3 were $49.27 \pm 0.24,35.78 \pm 0.49,40.29 \pm 0.56$ and $47.30 \pm 0.41 \mathrm{~mm}$, respectively. The difference in treatments was significant $(P<0.05)$. Visually, it was obvious that $\mathrm{T} 1$ showed the smallest colony diameter as compared with the other.

The difference among the treatments was analysed again from the perspective of the inhibitory rate. T1 exhibited the strongest antifungal activity during cultivation time (Fig. 3a). Its inhibitory rate was 1.16, 1.28 and 1.77 times that of $\mathrm{T} 2$ and 10.92, 45.02 and 7.91 times that of T3 at 24, 48 and $72 \mathrm{~h}$, respectively. The inhibitory 

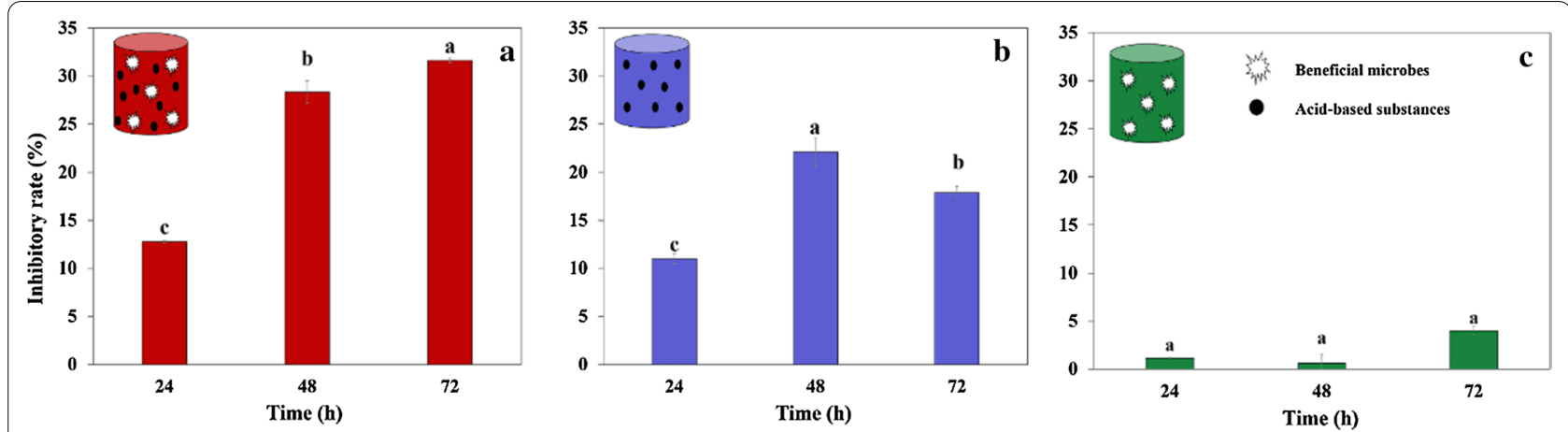

Fig. 3 Inhibitory rate of AJ against B. cinerea: a T1: AJ, a microbial ecosystem consisting of AS and BM; b T2: cell-free supernatant of AJ, only AS; $\mathbf{c} T 3$ : microbial solution of AJ, only BM

rate of $\mathrm{T} 1$ increased gradually with time, from $12.78 \%$ to $31.62 \%$ within $72 \mathrm{~h}(P<0.05)$. The inhibitory rate of $\mathrm{T} 2$ was between $\mathrm{T} 1$ and $\mathrm{T} 3$ and the value increased at the beginning and then decreased $(P<0.05)$. The peak appeared at $48 \mathrm{~h}$, with $22.11 \%$ (Fig. $3 \mathrm{~b}$ ). The inhibitory rate of T3 was low, but it showed an increasing trend. The inhibition rate increased from $1.17 \%$ to $4.00 \%$ during the inhibition process (Fig. 3c).

In general, the antifungal activity $\mathrm{AJ}$ was the most outstanding, with gradual stronger inhibition. The inhibitory rate of cell-free supernatant was lower than that of $\mathrm{AJ}$ at the early stage, and this value decreased remarkably at the late stage. Microbial solution had weak inhibition against the pathogen but showed an increasing tendency.

\section{Dynamic changes in $\mathrm{pH}, \mathrm{LA}$ and $\mathrm{AA}$ during the inhibition process}

To further reveal the antifungal mechanism of AJ, the concentrations of LA and AA and the $\mathrm{pH}$ were dynamically measured during the inhibition process (Fig. 4). Organic acids of $\mathrm{T} 1$ gradually accumulated, especially AA, whose concentration increased from 0.31 to $1.91 \mathrm{~g} / \mathrm{L}$. With the addition of AS of AJ, the initial $\mathrm{pH}$ value was only 5.10 and then reduced to $3.84(P<0.05)$.

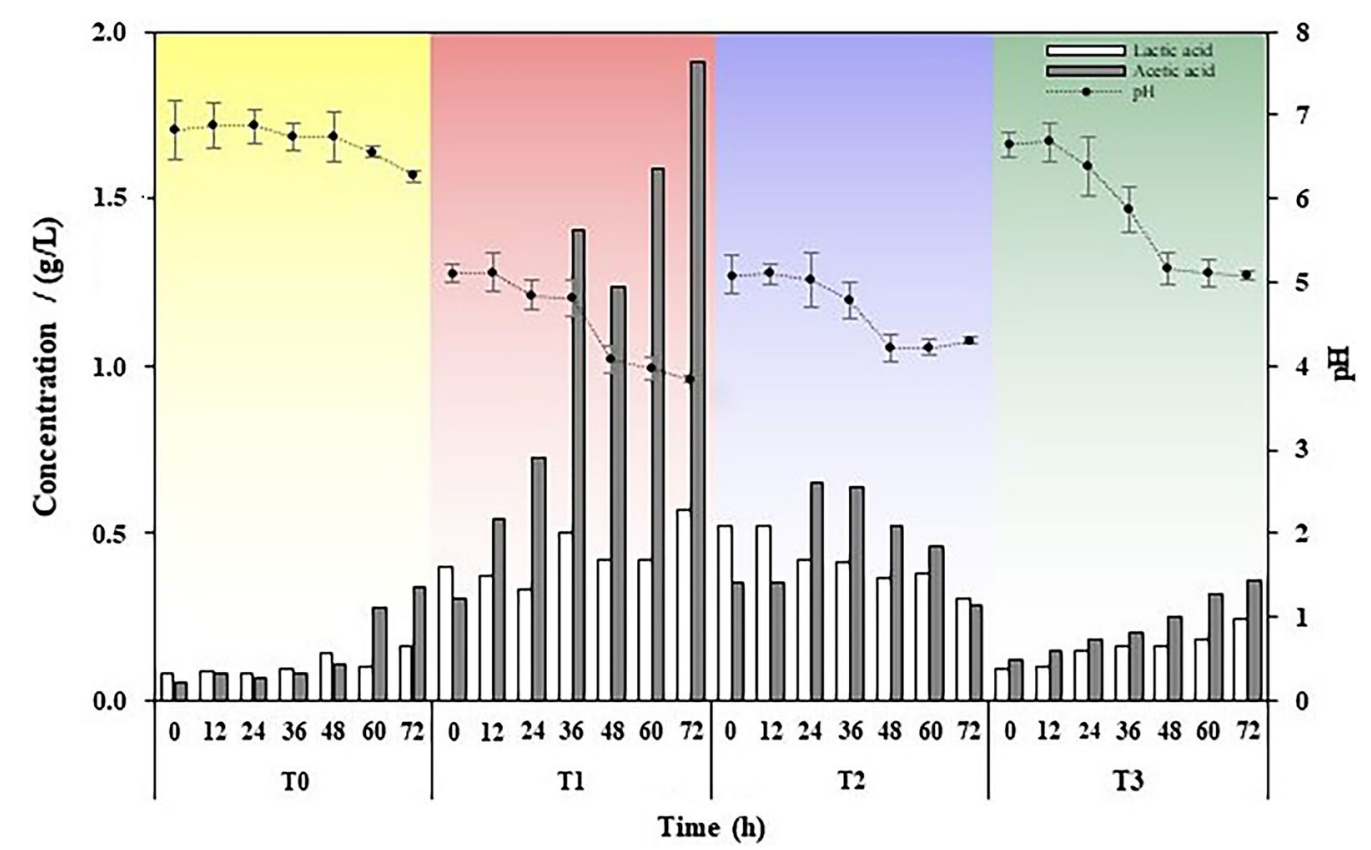

Fig. 4 Dynamic changes in the $\mathrm{pH}$ value and concentrations of $L A$ and $A A$ 
The concentration of LA showed a decline with cultivation time from 0.52 to $0.31 \mathrm{~g} / \mathrm{L}$. As for AA, there was a trend of increase first and then gradually decreased to $0.29 \mathrm{~g} / \mathrm{L}$. Finally, the concentration of AA was only $15.18 \%$ of T1. The main component of cell-free supernatant was AS, so the $\mathrm{pH}$ value was only 5.09 at the beginning. Subsequently, the value dropped temporarily and then increased. The lowest $\mathrm{pH}$ value was observed at $48 \mathrm{~h}$ (4.21). Microbial solution consisted of $\mathrm{BM}$ of AJ, such as Lactobacillus and Acetobacter. Compared to T1, LA and AA in T3 increased slightly. The concentration of AA was only $0.36 \mathrm{~g} / \mathrm{L}$ at $72 \mathrm{~h}$, which was $18.85 \%$ that of $\mathrm{T} 1$. The $\mathrm{pH}$ value dropped from 6.66 to 5.08 , which was equivalent to the initial value of $\mathrm{T} 1$.

In summary, the $\mathrm{pH}$ value and the concentration of AA displayed an apparent fluctuation during the inhibition process. $\mathrm{AJ}$ showed the lowest $\mathrm{pH}$ value and the strongest acid production capacity, especially AA.

\section{qPCR analysis of B. cinerea, Lactobacillus and Acetobacter during the inhibition process}

B. cinerea and the main strains of $\mathrm{AJ}$ (Lactobacillus and Acetobacter) in different periods were quantitated by qPCR (Fig. 5). B. cinerea of CK grew continuously, with gene concentrations from $1.80 \mathrm{E}+04$ to $4.27 \mathrm{E}+04$ copies/
$\mathrm{mL}$. In contrast, the pathogen was inhibited effectively during the inhibition process in $\mathrm{T} 1$, and the gene concentration decreased to $1.61 \mathrm{E}+03$ copies $/ \mathrm{mL}$. Simultaneously, Acetobacter in AJ increased exponentially and rapidly became the dominant microorganism, whose gene concentration reached a peak at $60 \mathrm{~h}(6.72 \mathrm{E}+10$ copies $/ \mathrm{mL}$ ) from $1.68 \mathrm{E}+08$ copies $/ \mathrm{mL}$ at $0 \mathrm{~h}$. Cell-free supernatant (T2) showed an inhibitory effect at the early stage. The gene concentration of the pathogen decreased to $2.89 \mathrm{E}+03$ copies $/ \mathrm{mL}$ within $48 \mathrm{~h}$ and then recovered to $3.16 \mathrm{E}+04$ copies $/ \mathrm{mL}$. Microbial solution (T3) had a weak influence on the growth of $B$. cinerea, with the highest gene concentration of $3.27 \mathrm{E}+04$ copies $/ \mathrm{mL}$ at $72 \mathrm{~h}$.

In summary, AJ could inhibit the pathogen effectively and persistently. Acetobacter rapidly proliferated and occupied the dominant niche, thus inhibiting the growth of the pathogen by metabolising a large amount of AA. This conclusion was consistent with the results of Fig. 4.

\section{Contribution rates of $A S$ and $B M$ of $A J$ and their synergistic effect}

In Fig. 3, the final antifungal activity of AJ (T1) was better than that of cell-free supernatant (T2) and microbial solution (T3). Additional file 1: Fig. S2 was obtained by comparing T2 and T3 to T1. The red area in the columns

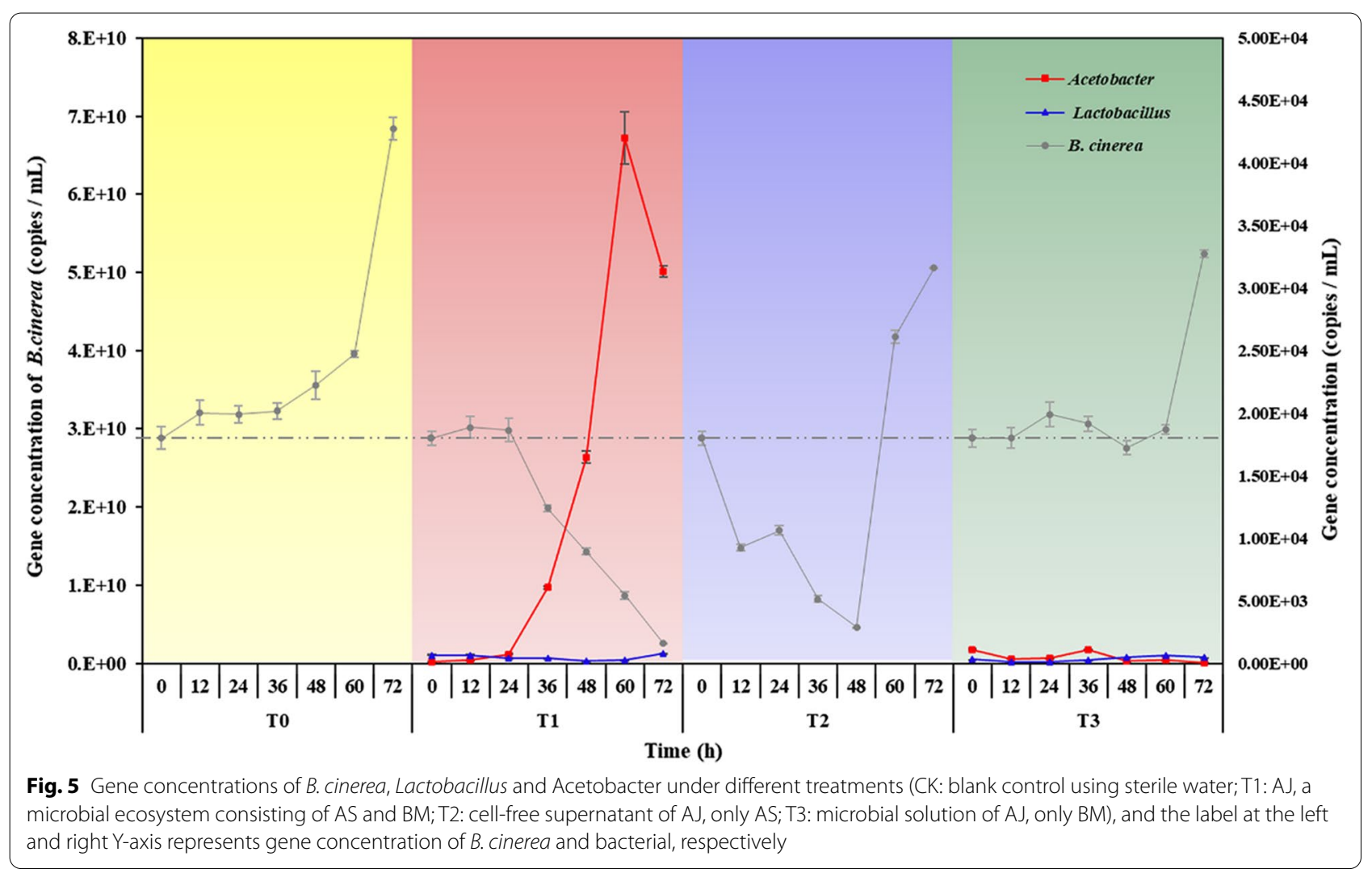



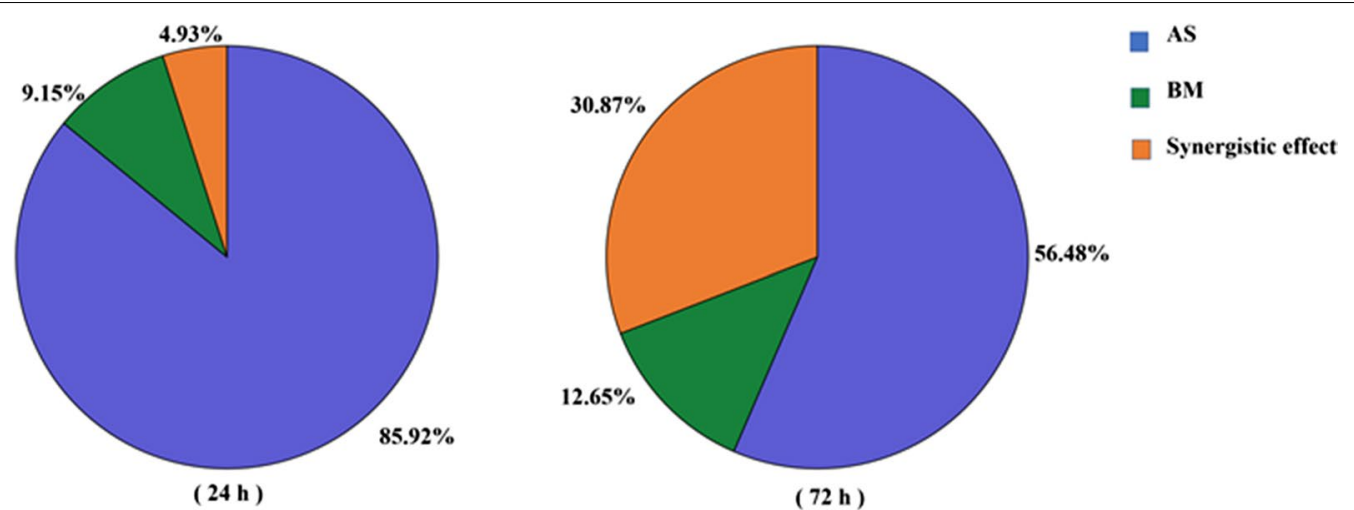

( 24 h )

( 72 h )

Fig. 6 Contribution rate of AS and BM and their synergistic effect

represents the increase part of the inhibitory rate of AJ compared to that of the cell-free supernatant and microbial solution. At the early stage $(24 \mathrm{~h})$ and late stage (72 h), AJ increased the inhibitory rate by $21 \%$ and $77 \%$ compared to cell-free supernatant and 9.41 and 6.91 times compared to microbial solution. These results showed that AJ, as an ecosystem of AS and BM, had a stronger inhibitory effect against $B$. cinerea.

When the inhibitory rates of T2 and T3 were added, the sum was less than the inhibitory rate of T1. This difference was considered as a synergistic effect of AS and BM. Figure 6 shows the percentage of the contribution rate of $\mathrm{AS}$ and BM and their synergistic effect at the beginning and end. AS accounted for the largest proportion at $24 \mathrm{~h}$ and then declined from $85.92 \%$ to $56.48 \%$. Conversely, the contribution rate of BM increased gradually with prolonged cultivation time, with the value increasing from $9.15 \%$ to $12.65 \%$. Likewise, the proportion of synergistic effects also had a sharp increase, which reached $30.78 \%$ at the late stage $(72 \mathrm{~h})$.

In summary, AS were the main inhibitory factor at the early stage. BM gradually played a vital role at the late stage, which led to an increased proportion of the synergistic.

\section{Discussion}

AJ not only has a strong antifungal activity but also provides a high-value-added treatment strategy of organic wastes, which achieves the dual role of resource utilisation and safety production. This product has the advantages of green, low-cost and easy operation and has been widely applied in rural China in recent years (Zhang et al. 2020). In this study, the antifungal activity and mechanism of $\mathrm{AJ}$ on $B$. cinerea were investigated. The following points were discussed based on the comprehensive analysis of the results.
AS and BM and their synergistic effect contributed to the antifungal activity of $\mathrm{AJ}$ against $B$. cinerea. $\mathrm{AJ}$ is a fermentation ecosystem that integrates AS (LA and AA) and BM (Lactobacillus and Acetobacter). When AS and $\mathrm{BM}$ of AJ were separated, the two fractions still showed an inhibitory effect. These results suggested that AS and $\mathrm{BM}$ are the key inhibitory factors. Acetobacter was the antagonistic microorganism that played a major role during the late stage of the inhibition process (Fig. 5). Also, the inhibitory effect of $\mathrm{AJ}$ was more favourable than that of cell-free supernatant and microbial solution, which indicated that the synergistic effect between AS and BM is another factor that could not be ignored.

Figure 2 shows that the antifungal activity of AJ was positively correlated with dosage. The production of $\mathrm{AJ}$ is a fermentation process dominated by BM in which sugar is converted into organic acids and the acids gradually accumulate (Arun and Sivashanmugam 2015; Selvakumar and Sivashanmugam 2018). Our results also proved that $\mathrm{AJ}$ was an ecosystem that contains AS, mainly LA and AA (Table 1). The organic acids can change the permeability of the cell membrane of the pathogen, make antifungal components such as AA enter the target pathogen (Hashemi et al. 2017), reduce the cytoplasmic pH, suspend cell metabolism and directly inhibit the growth of the pathogen (Dalié et al. 2010; Yamaji et al. 2005). The inhibitory rate of $\mathrm{AJ}$ increased with dosage, which may be related to the concentrations of organic acids. When AJ was added to PDA medium at the ratio of $5 \%$, the concentration of LA and AA was 0.23 and $0.08 \mathrm{~g} / \mathrm{L}$, respectively. The concentration of the two organic acids increased by 10 times when the ratio was $50 \%$.

The antifungal activity of $\mathrm{AJ}$ changed with cultivation time (Figs. 2 and 3; Table 2). AJ (an ecosystem of AS and $\mathrm{BM})$ had the strongest inhibitory effect and became gradually stronger. Cell-free supernatant (only AS) showed slightly lower performance than $\mathrm{AJ}$ at the early stage, and 


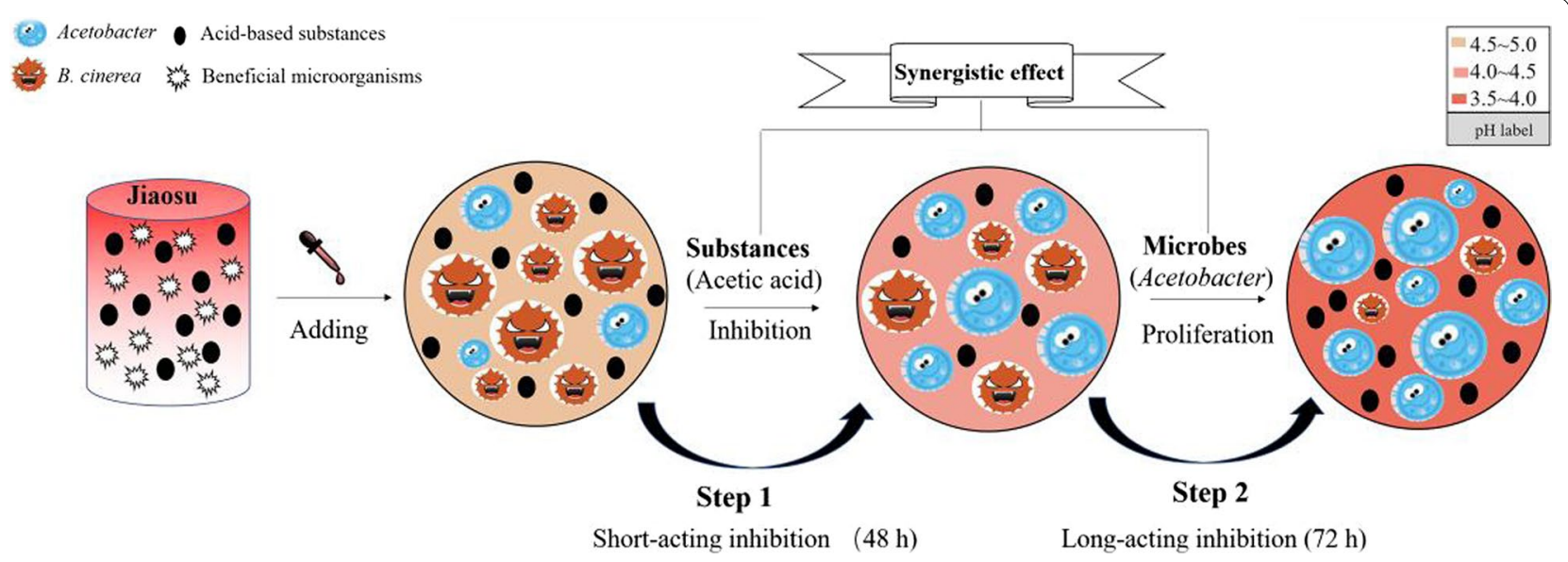

Fig. 7 'Two-step inhibition' antifungal mode of AJ

the inhibition rate was significantly reduced at the late stage. The antifungal activity of microbial solution (only BM) was weak, but it showed a slightly stronger characteristic after $48 \mathrm{~h}$. In Fig. 2, the inhibitory rate of the three treatments at $72 \mathrm{~h}$ was higher than at $24 \mathrm{~h}$, which also proved that the inhibitory effect of AJ gradually stronger. Moreover, Fig. 3 also shows that the antifungal activity of $\mathrm{AJ}$ increased with cultivation time. AS in $\mathrm{AJ}$ inhibited the pathogen effectively in a short time and BM of AJ, especially Acetobacter, occupied the niche simultaneously.

The inhibitory effect of cell-free supernatant increased at first and then decreased (Fig. 3b). The qPCR results revealed that the genes of Lactobacillus and Acetobacter were not detected in T2, which indicated that the microorganisms of AJ had been removed (Kazemipoor et al. 2012; Li et al. 2013), and AS performed antifungal activity mainly at this time (Chen et al. 2007; Stoianova et al. 2012). AS have a positive impact on antifungal activity (Golnaz Hesami 2013; De Corato et al. 2014). However, previous studies have shown that organic acids can be consumed or transformed by microorganisms as carbon sources during natural fermentation (Rao et al. 2020; Zacharof and Lovitt 2012; Huang et al. 2016; Liu et al. 2008; Baskaran et al. 2002); thus, the antifungal activity became weak. Figure 4 also illustrated this conclusion in which the concentration of LA and AA decreased in T2 during the inhibition process. This result was similar to the results of Liu et al. (2006); when the concentration of AA in fermented broth was reduced from 4.27 to $4.14 \mathrm{~g} / \mathrm{L}$ and that of LA was decreased from 17.45 to $17.32 \mathrm{~g} / \mathrm{L}$, the diameter of the bacteriostatic zone declined from 36 to $26 \mathrm{~mm}$.

Compared to cell-free supernatant and AJ, the antifungal activity of microbial solution increased slightly with cultivation time. Probiotics often coexist with harmful bacteria and play a beneficial role only when they occupy the niche (Oh et al. 2017). Figure 5 shows that the gene concentration of Lactobacillus and Acetobacter was extremely low during the inhibition process. Therefore, $\mathrm{BM}$ of $\mathrm{AJ}$ failed to become the dominant bacteria by overcoming the vigorous growth of $B$. cinerea. However, Lactobacillus and Acetobacter were active and metabolised a small amount of organic acids (Fig. 4). Then, the $\mathrm{pH}$ value decreased slightly and the inhibitory rate increased at the late stage.

There was a synergistic effect between AS and BM, which led AJ to have a ' $1+1>2$ ' inhibitory effect. Figure 6 shows that the antifungal activity of AS became weaker and weaker, whereas the contribution rate of $\mathrm{BM}$ increased gradually. This is because the inhibitory effect of cell-free supernatant was weakened by a decreased concentration of AS. Similar studies have been reported. The antibacterial effect of the supernatant of $L A B$ fermentation became weaker with the decrease of LA and AA ( $\mathrm{Li}$ et al. 2008; Li et al. 2006). However, Acetobacter rapidly propagated and continuously produced AA, which indirectly affected the growth of B. cinerea (Lefeber et al. 2011; Myresiotis et al. 2007). Meanwhile, the contribution rate of the synergistic effect also increased by 5.62 times. This was the similar with the results of Tadijan et al. (2016), the inhibitory effect of antagonistic microorganisms on the phytopathogenic fungus was gradually enhanced within $72 \mathrm{~h}$.

Based on the above analysis, an antifungal mode called 'two-step inhibition' of AJ was proposed, as shown in Fig. 7. AJ was rich in AS (AA and LA) and BM (Acetobacter and Lactobacillus). When AJ was added to the medium dominated by phytopathogens, AS inhibited the growth of the pathogen directly at the early 
stage $(48 \mathrm{~h})$ and provided a dominant niche for BM in AJ simultaneously. With the consumption or transformation of AS, the inhibitory effect gradually weakened. However, BM in AJ, especially Acetobacter, rapidly propagated and became the dominant bacteria under this condition. Then, a large amount of AA was metabolised continuously, which is a recognized as a good antibacterial substance. Therefore, AJ achieved highefficiency and long-acting antifungal activity through this synergistic effect between AS and BM.

\section{Supplementary information}

The online version contains supplementary material available athttps://doi. org/10.1186/s13568-020-01156-7.

Additional file 1.: Table S1. Summary of qPCR primers. Table S2. Cycling protocols of qPCR. Fig. S1. IC $C_{50}$ of AJ against B. cinerea. Broken, horizontal and vertical lines represent the fitting line, half of the colony diameter of CK and the corresponding dosages, respectively. Black and red circles represent the observed value and the $\mathrm{IC}_{50}$, respectively. Fig. S2. Increase part of the inhibitory rate of AJ. Blue and green bar represents the inhibitory rate of $A S(T 2)$ and $B M(T 3)$ respectively. And the red bar represents the higher part of inhibitory rate of AJ compared to the AS and BM.

\section{Acknowledgements}

This study was supported by the National Key Research and Development Program (Grant Number: 2019YFC0408700).

\section{Authors' contributions}

Conceptualization: $Y Z, X W$, Methodology: $Y Z$; Formal analysis and investigation: $Y Z$; Writing —original draft preparation: $Y Z ; W r i t i n g$ - review and editing: YG, ZZ, XM, YC, JL, YH, SY, XW; Funding acquisition: XW; Resources: XW; Supervision: YC, ZZ, XW. All authors read and approved the final manuscript.

\section{Funding}

This study was supported by the National Key Research and Development Program of China (Grant Number: 2019YFC0408700).

\section{Availability of data and materials}

All data and material generated or analysed during this study are included in this published article

\section{Ethics approval and consent to participate}

This article does not contain studies with human participants or animals by any of the authors.

\section{Consent for publication}

The authors declare that they agree for publication.

\section{Competing interests}

The authors declare that they have no conflict of interest.

\section{Author details}

${ }^{1}$ College of Agronomy and Biotechnology, China Agricultural University, Beijing 100193, China. ${ }^{2}$ Beijing Technology and Business University, Beijing 100048, China. ${ }^{3}$ Department of Biochemical Conversion, Deutsches Biomassforschungszentrum gemeinnütziges $\mathrm{GmbH}$, Torgauer Straße 116, 04347 Leipzig, Germany. ${ }^{4}$ Institute of Plant Nutrition and Resources, Beijing Academy of Agricultural and Forestry Sciences, Beijing 100097, China. ${ }^{5} \mathrm{Col}-$ lege of Resource and Environmental Science, Shanxi Agricultural University, Shanxi 030801, China.
Received: 26 November 2020 Accepted: 4 December 2020

Published online: 14 December 2020

\section{References}

Aqueveque P, Céspedes CL, Becerra J, Aranda M, Sterner O (2017) Antifungal activities of secondary metabolites isolated from liquid fermentations of Stereum hirsutum (Sh134-11) against Botrytis cinerea (grey mould agent). Food Chem Toxicol 109:1048-1054

Arun C, Sivashanmugam P (2015) Identification and optimization of parameters for the semi-continuous production of garbage enzyme from pre-consumer organic waste by green RP-HPLC method. Waste Manage 44:28-33

Baraldi E, Bertolini P, Chierici E, Trufelli B, Luiselli D (2002) Genetic diversity between Botrytis cinerea Isolates from Unstored and Cold Stored Kiwi fruit. J Phytopathol 150(11-12):629-635

Baskaran D, Ilango I, Sivakumar S (2002) Effect of time of incubation on the antibacterial acitivity of cell free culture filtrates of Lactobacilli anainst Escherichia coli. Cherion 5-6(31):149-150

Ben-Shalom N, Ardi R, Pinto R, Aki C, Fallik E (2003) Controlling gray mould caused by Botrytis cinerea in cucumber plants by means of chitosan. Crop Prot 22(2):285-290

Bi Y, Yu Z (2016) Diterpenoids from Streptomyce sp SN194 and their antifungal activity against Botrytis cinerea. J Agr Food Chem 64(45):8525-8529

Cai Y, Zheng Z, Zhao Y, Zhang Y, Guo S, Cui Z, Wang X (2018a) Effects of molybdenum, selenium and manganese supplementation on the performance of anaerobic digestion and the characteristics of bacterial community in acidogenic stage. Bioresour Technol 266:166-175

Cai Y, Wang J, Zhao Y, Zhao X, Zheng Z, Wen B, Cui Z, Wang X (2018b) A new perspective of using sequential extraction: to predict the deficiency of trace elements during anaerobic digestion. Waste Res 140:335-343

Chen S, Xia Y, Nie Q (2007) Research on antibacterial capability of lactic acid bacteria in fermented vegetables. Food Eng 02:6-9 (in Chinese)

Dalié DKD, Deschamps AM, Richard-Forget F (2010) Lactic acid bacteriapotential for control of mould growth and mycotoxins: a review. Food Control 21(4):370-380

De Corato U, Viola E, Arcieri G, Valerio V, Cancellara FA, Zimbardi F (2014) Antifungal activity of liquid waste obtained from the detoxification of steam-exploded plant biomass against plant pathogenic fungi. Crop Prot 55:109-118

De Vuyst L, Leroy F (2020) Functional role of yeasts, lactic acid bacteria and acetic acid bacteria in cocoa fermentation processes. FEMS Microbiol Rev 44(4):432-453

Di P, Peng Y, Li C, Lu H, Gu X, Tian H (2020) Diversity analysis of microorganisms of mulberry Jiaosu based on metagenomics. J Chin Inst Food Sci Technol 20(05):251-257 (in Chinese)

Drysdale GS, Fleet GH (1989) The effect of acetic acid bacteria upon the growth and metabolism of yeasts during the fermentation of grape juice. J Bacteriol 67(5):471-481

Golnaz Hesami SH (2013) Effect of Pistacia atlantica subsp. kurdica essential oil and acetic acid on Botrytis cinerea growth in culture media, grape and cucumber fruits. IJMM 2(1):13-21

Guo S (2019) Characteristics of anaerobic co-digestion of pig manure and cracked jujube and dynamic change of gibberellin in biogas slurry. Dissertation, China Agricultural University, Beijing

Haarman M, Knol J (2006) Quantitative real-time pcr analysis of fecal Lactobacillus species in infants receiving a prebiotic infant formula. Appl Environ Microbiol 72(4):2359-2365

Hashemi SMB, Mousavi Khaneghah A, Barba FJ, Nemati Z, SohrabiShokofti S, Alizadeh F (2017) Fermented sweet lemon juice (Citrus limetta) using Lactobacillus plantarum LS5: chemical composition, antioxidant and antibacterial activities. J Funct Foods 38:409-414

Huang X, Liu J, Lu L, Peng K, Yang G, Liu J (2016) Culture strategies for lipid production using acetic acid as sole carbon source by Rhodosporidium toruloides. Bioresour Technol 206:141-149 
Jeong M, Bae D, Bae H, Lee SI, Kim JA, Shin SC, Park SH, Park S (2013) Inhibition of Botrytis cinerea spore germination and mycelia growth by frequencyspecific sound. J Korean Soc Appl Bi 56(4):377-382

Kazemipoor M, Radzi CWJW, Begum K, Yaze I (2012) Screening of antibacterial activity of lactic acid bacteria isolated from fermented vegetables against food borne pathogens. Archives Des Sci 65(6):192-201

Kuwaki S, Ohhira I, Takahata M, Murata Y, Tada M (2002) Antifungal activity of the fermentation product of herbs by lactic acid bacteria against tinea. J Biosci Bioeng 94(5):401-405

Lagopodi AL, Cetiz K, Koukounaras A, Sfakiotakis EM (2009) Acetic acid, ethanol and steam effects on theg of Botrytis cinerea in vitro and combination of steam and modified atmosphere packaging to control decay in kiwifruit. J Phytopathol 157(2):79-84

Lee JP, Lee S, Kim CS, Son JH, Song JH, Lee KY, Kim HJ, Jung SJ, Moon BJ (2006) Evaluation of formulations of Bacillus licheniformis for the biological control of tomato gray mold caused by Botrytis cinerea. Biol Control 37(3):329-337

Lefeber T, Gobert W, Vrancken G, Camu N, De Vuyst L (2011) Dynamics and species diversity of communities of lactic acid bacteria and acetic acid bacteria during spontaneous cocoa bean fermentation in vessels. Food Microbiol 28(3):457-464

Li WT, Fan JX, Li WH, Yuan H (2013) Antifungal mechanism of cow manure biogas slurry on Rhizoctonia solani. Trans Chin Soc Agric Eng 29(03):207212 (in Chinese)

Liu D, Wu H, Li Yang X (2006) Study on relationship between the organic acid produced by L. rhamnosus and its inhibitory effects. Acad Period Farm Prod Process 10:111-114 (in Chinese)

Liu D, Wu H, Li L, Liang S (2008) Antimicrobial activity of Lactobacillus casei (rhamnosus) and optimization of its fermentation conditions for optimal inhibitory effects. Food Chem 29(6):237-242 (in Chinese)

Ministry of Industry and Information Technology of the People's Republic of China(MIIT-China): Beijing, China (2018) Light industry standards of the People's Republic of China: Plant Jiaosu (No. QB/T 5323-2018)

Ministry of Industry and Information Technology of the People's Republic of China(MIIT-China): Beijing, China (2018) Light industry standards of the People's Republic of China: Guideline for Jiaosu products classification (No. QB/T 5324-2018)

Myresiotis CK, Karaoglanidis GS, Tzavella-Klonari K (2007) Resistance of Botrytis cinerea isolates from vegetable crops to anilinopyrimidine, phenylpyrrole, hydroxyanilide, benzimidazole, and dicarboximide fungicides. Plant Dis 91(4):407-413

Oh B, Jeong S, Velmurugan P, Park J, Jeong D (2017) Probiotic-mediated blueberry (Vaccinium corymbosum L.) fruit fermentation to yield functionalized products for augmented antibacterial and antioxidant activity. J Biosci Bioeng 124(5):542-550

Panebianco A, Castello I, Cirvilleri G, Perrone G, Epifani F, Ferrara M, Polizzi G, Walters DR, Vitale A (2015) Detection of Botrytis cinerea field isolates with multiple fungicide resistance from table grape in Sicily. Crop Prot 77:65-73

Rahman S, Haque I, Goswami RCD, Barooah P, Sood K, Choudhury B (2020) Characterization and FPLC analysis of garbage enzyme: biocatalytic and antimicrobial activity. Waste Biomass Valor. https://doi.org/10.1007/s1264 9-020-00956-Z

Rao Y, Qian Y, Tao Y, She X, Li Y, Chen X, Guo S, Xiang W, Liu L, Du H, Xiao $H(2020)$ Characterization of the microbial communities and their correlations with chemical profiles in assorted vegetable Sichuan pickles. Food Contorl 113:101174

Rosado-Álvarez C, Molinero-Ruiz L, Rodríguez-Arcos R, Basallote-Ureba MJ (2014) Antifungal activity of asparagus extracts against phytopathogenic Fusarium oxysporum. Sci Hortic 171:51-57

Santos A, Sánchez A, Marquina D (2004) Yeasts as biological agents to control Botrytis cinerea. Microbiol Res 159(4):331-338

Selvakumar P, Sivashanmugam P (2017) Optimization of lipase production from organic solid waste by anaerobic digestion and its application in biodiesel production. Fuel Process Technol 165:1-8

Selvakumar P, Sivashanmugam P (2018) Multi-hydrolytic biocatalyst from organic solid waste and its application in municipal waste activated sludge pre-treatment towards energy recovery. Process Saf Environ 117:1-10

Stoianova LG, Ustiugova EA, Netrusov Al (2012) Antibacterial metabolites of lactic acid bacteria: their diversity and properties. Prikl Biokhim Mikrobiol 48(3):259-275

Sun Z, Yang L, Han M, Han Z, Yang L, Cheng L, Yang X, Lv Z (2019) Biological control ginseng grey mold and plant colonization by antagonistic bacteria isolated from rhizospheric soil of Panax ginseng Meyer. Biol Control 138:104048

Tadijan I, Grahovac J, Dodić J, Grahovac M, Dodić S (2016) Effect of cultivation time on production of antifungal metabolite(s) by Streptomyces hygroscopicus in laboratory-scale bioreactor. J Phytopathol 164(5):310-317

Trias R, Baneras L, Montesinos E, Badosa E (2008) Lactic acid bacteria from fresh fruit and vegetables as biocontrol agents of phytopathogenic bacteria and fungi. Int Microbiol 11(4):231-236

Xu H, Fu Y, Li T, Wand R (2017) Effects of different LED light wavelengths on the resistance of tomato against Botrytis cinerea and the corresponding physiological mechanisms. J Integr Agr 16(1):106-114

Yamaji K, Ishimoto H, Usui N, Mori S (2005) Organic acids and water-soluble phenolics produced by Paxillus sp 60/92 together show antifungal activity against $P$ ythium vexans under acidic culture conditions. Mycorrhiza 15(1):17-23

Yildirm I, Yapici BML (2007) Inhibition of conidia germination and mycelial growth of Botrytis cinerea by some alternative chemicals. Pak J Agr Scei 10(8):1294-1300

Zacharof MP, Lovitt RW (2012) Bacteriocins produced by lactic acid bacteria: a review article. Apcebee Procedia 2:50-56

Zhang Y, Zhao Y, Cai Y, Liu X, Hu Y, Wang X (2020) Ecological effects of plant Jioasu for agriculture: a review. J Chin Agric Univ 03(04):25-35 (in Chinese)

Zhao Y, Yu J, Liu J, Yang H, Gao L, Yuan XF, Hu Y, Cui Z, Wang X (2016) Material and microbial changes during corn stalk silage and their effects on methane fermentation. Bioresour Technol 222:89-99

Zhao X, Liu J, Liu J, Yang F, Zhu W, Yuan X, Hu Y, Cui Z, Wang X (2017) Effect of ensiling and silage additives on biogas production and microbial community dynamics during anaerobic digestion of switchgrass. Bioresour Technol 241:349-359

\section{Publisher's Note}

Springer Nature remains neutral with regard to jurisdictional claims in published maps and institutional affiliations. 